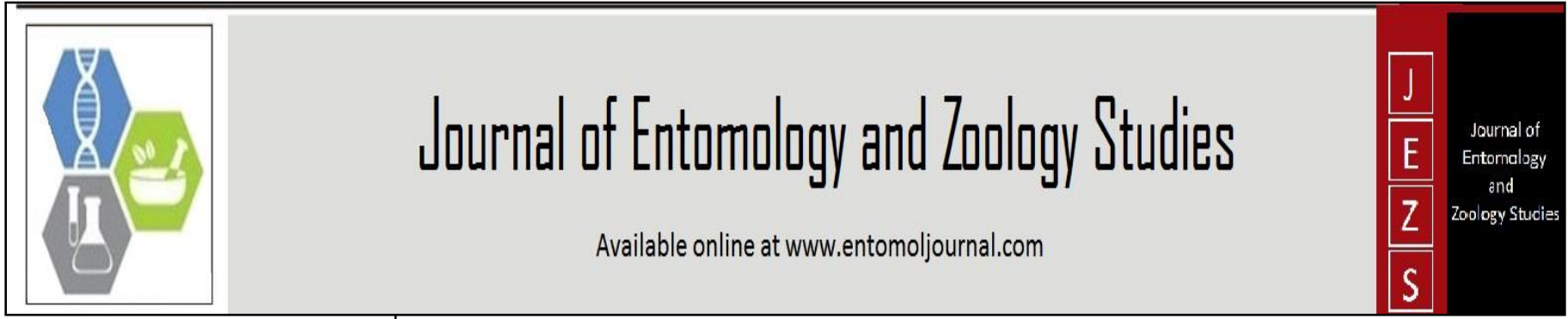

E-ISSN: 2320-7078

P-ISSN: 2349-6800

www.entomoljournal.com JEZS 2021; 9(2): 1094-1098 (C) $2021 \mathrm{JEZS}$

Received: 10-01-2021

Accepted: 12-02-2021

Dipak D Barsagade

Department of Zoology, M.J.F.

Educational Campus, R.T.M.

Nagpur University Nagpur,

Maharashtra, India

Vilas R Jiwatode

Department of Zoology, M. J.F.

Educational Campus, R.T.M.

Nagpur University Nagpur,

Maharashtra, India
Corresponding Author:

Vilas R Jiwatode

Department of Zoology, M.J.F.

Educational Campus, R.T.M.

Nagpur University Nagpur,

Maharashtra, India

\section{Effect of juvenile hormone-III and 20- hydroxyecdysone hormone on larval development of worker and drone honeybee Apis cerana indica (Fabricius) (Hymenoptera: Apidae)}

\section{Dipak D Barsagade and Vilas R Jiwatode}

DOI: https://doi.org/10.22271/j.ento.2021.v9.i2m.8582

\begin{abstract}
Indian honeybee Apis cerana indica is polymorphic bee having queen, worker and drone castes. In honeybee each caste has its own developmental pattern and completes its development passing through egg larva, pupa and adult stages. Post-embryonic development of honeybee is controlled by juvenile hormone and 20-hydroxyecdysone. Present study find out the effects of juvenile hormone-III and 20hydroxyecdysone on development of fifth instar larvae of worker and drone honeybee Apis cerana indica. Pattern of effects of both hormones on weight and length of worker and drone larvae were observed similar at $24 \mathrm{hrs}$ and $36 \mathrm{hrs}$ time interval but prominent changes in weight and length were seen in drone larvae as compared to worker larvae. Antagonistic effect of juvenile hormone-III and 20hydroxyecdysone on total body protein was found in worker and drone larvae. Different effects of both hormones on worker and drone larvae suggested the different development timing and differed in physiology of worker and drone castes.
\end{abstract}

Keywords: Apis cerana indica, juvenile hormone-III, larvae, 20- hydroxyecdysone

\section{Introduction}

Juvenile hormone play important role during caste development of honeybee, Apis mellifera (Wirtz and Beetsma, 1972; Wirtz 1973; Copijn et al., 1979; Dietz et al., 1979; Rachinsky et al., 1990) ${ }^{[20,21,5,6,12]}$. Rembold et al., $1974^{[13]}$ found disturbed development in juvenile hormone treated larvae of Apis mellifera. Asencot and Lansky (1976) ${ }^{[1]}$ observed different effect of juvenile hormone with different concentration of sugar on the differentiation of worker larvae to queen. Salles and Cruz-Landim (2004) ${ }^{[15]}$ found no significant effect of juvenile hormone on the morphology of mandibular gland in fifth instar larvae of worker honeybee Apis mellifera. Physiological effect of juvenile hormone on adult honeybee Apis mellifera was observed by Rachinsky et al., (1990) ${ }^{[12]}$. Rutz et al., (1975) ${ }^{[14]}$ found that high dose of $10 \mu \mathrm{g}$ of JH-III decreased haemolymph protein concentration, lowers the vitellogenin synthesis and degenerate the hypopharyngeal gland while low dose of $1 \mu \mathrm{g}$ of JH-III increase the haemolymph protein concentration, vitellogenin synthesis and development of hypopharyngeal gland.

Decrease protein contents and protein patterns of mucus gland were observed by Colonella and Hartfelder (2003) [4] in adult honeybee drone Apis mellifera after treatment with 20hydroxyecdysone. A stimulatory and inhibitory effect of 20-hydroxyecdysone hormone was also noticed in other insects (Shridevi et al., 1990; Ismail and Dutta-Guota, 1990; Ismail and Gillot 1995; 1997) ${ }^{[7,8,9]}$. Nascimento et al., (2003) ${ }^{[11]}$ describe the inhibitory effect of 20 hydroxyecdysone and no effect of juvenile hormone on expression of transferring gene during postembryonic development of honeybee Apis mellifera.

Apis cerana indica is highly domesticated honeybee in India for commercial and pollination purpose. It is polymorphic bee having queen, worker and drone castes. Each caste has its own developmental pattern. Therefore the present study is focused on to study the effects of juvenile hormone-III (JH-III) and 20-hydroxyecdysone (20-HE) on development of fifth instar larvae of worker and drone caste. All statistics presented in this paper is mean \pm of standard errors. Students " $\mathrm{t}$ " test was made use for testing the significance of difference between the 
mean of reading of experiments and control groups. The probability of significance ( $p$ value) was calculated from the fisher's table of “t” values (Steel and Torrie 1960) ${ }^{[18]}$.

\section{Material and Method}

Material: Fifth instar larvae of worker and drone honeybee Apis cerana indica colony from home apiary were used for weight and length measurement and total body protein quantification.

To obtained uniform aged larvae of worker and drone caste, queen honey bee was restricted to two broodless combs for several hrs for eggs deposition. After completion of fourth moult ( $5^{\text {th }}$ day) brood frame containing fifth instar larvae were removed from hive. Worker and drone larvae were grouped and marked for identification.

Juvenile hormone-III and 20-hydroxyecdysone were topically applied to fifth instar larvae of both castes.
1. Juvenile hormone-III treatment: $1 \mathrm{mg}$ juvenile hormoneIII (JH-III Sigma, USA cat no- J2000) was dissolved in $1 \mathrm{ml}$ cold acetone and $1 \mu \mathrm{L}$ of JH-III was applied topically to each fifth instar larva of worker and drone honeybee (first group).

2. 20-hydroxyecdysone hormone treatment: $1 \mathrm{mg} 20$ hydroxyecdysone (Sigma, USA cat no- H5142) was dissolved in $1 \mathrm{ml}$ cold acetone and $1 \mu \mathrm{L}$ of 20 -hydroxyecdysone was applied topically to each fifth instar larva of both castes (second group).

3. Acetone treatment (control): $1 \mu \mathrm{L}$ acetone was applied topically to each fifth instar larva of both castes (third group). Treated brood frames were allowed to acetone evaporation and then placed in hive. After $24 \mathrm{hrs}$ and $36 \mathrm{hrs}$ respectively, live five larval instar of both caste from each group were removed from frame and proceed for experimental parameters.

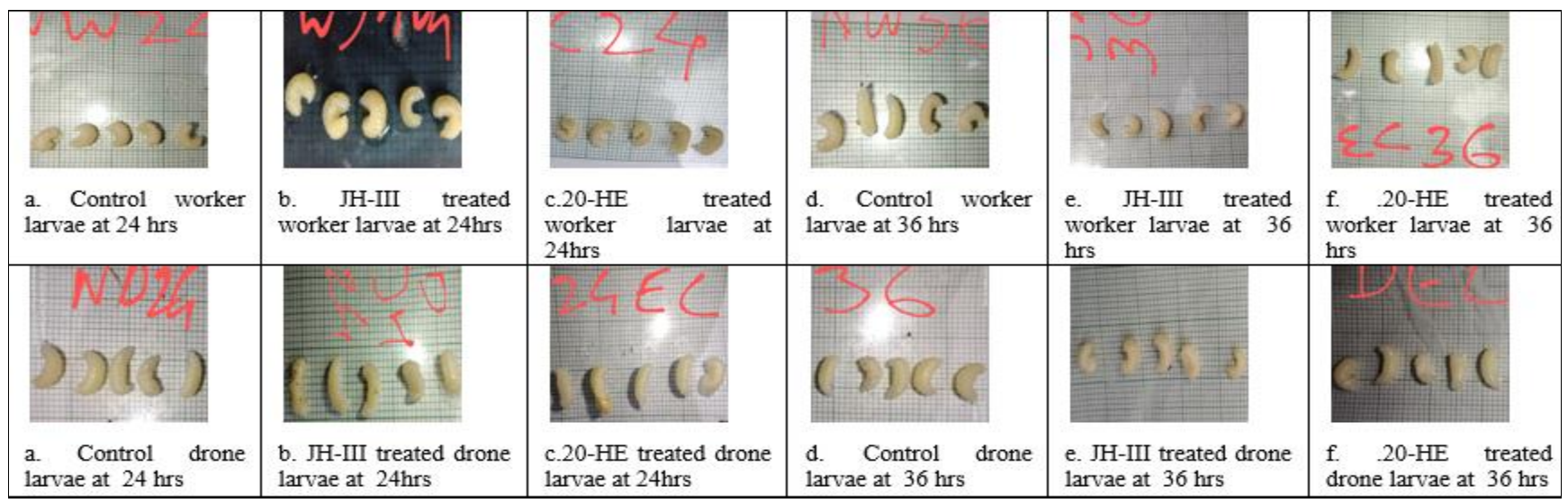

Fig 1: Fifth instar larvae of worker and drone honeybee Apis cerana indica treated by JH-III and 20-HE at 24 hrs and 36 hrs. (Control-acetone treated larvae. JH-III- Juvenile hormone-III. 20-HE - 20-hydroxyecdysone.)

\section{Method \\ Protein extraction}

Five larvae of each worker and drone were weighed and added in $500 \mu \mathrm{L}$ of homogenized buffer. Larval sample were homogenized with motor driven tissue grinder in cold homogenization buffer (TNE buffer-20 mM TRis-HCL, 400 $\mathrm{mM}$ Nacl, 5mM EDTA, $\mathrm{pH}$ 7.5) containing protease inhibitor cocktail. Homogenized solution was centrifuged for $10 \mathrm{~min}$ at $10000 \mathrm{rpm}$ at $4^{0} \mathrm{C}$ and supernatant was collected. Supernatant was centrifuged at $14000 \mathrm{rpm}$ at $4{ }^{\circ} \mathrm{C}$ for $10 \mathrm{~min}$. and again supernatant was collected. Aqueous layer from supernatant obtained after second centrifugation was stored at $-80{ }^{\circ} \mathrm{C}$ for total protein estimation. Total protein concentration from aqueous layer was determined by Bradford method (1976).
Observation

\section{Effect of JH-III and 20-HE on weight and length of} larvae

After topical application of JH-III, at $24 \mathrm{hrs}$ no prominent change in weight of fifth instar larvae of worker and drone honeybee were observed but at $36 \mathrm{hrs}$ after JH-III treatments slightly decrease in weight of both castes of larvae were seen. Slightly increase in weight of fifth instar larvae of both castes were observed after topical application of 20-HE at $24 \mathrm{hrs}$ but prominent increase in weight were observed in both caste larvae after $36 \mathrm{hrs}$ treatments with 20-HE. (Table 1 and Fig.2) At $24 \mathrm{hrs}$ in JH-III treated larvae and 20-HE treated larvae of both caste no change in length were observed as compared to control larvae. At $36 \mathrm{hrs}$, JH-III treated larvae of both caste shows slightly increase in length while 20-HE treated fifth instar larvae of both caste shows prominent decrease in body length. (Table 1 and Fig.3)

Table 1: Showing the weight $(\mathrm{mg})$ and length $(\mathrm{mm})$ of fifth instar larvae of worker and drone after topical application of juvenile hormone-III (JH-III) and 20 hydroxyecdysone hormone (20-HE). Control experiment was performed with acetone.

\begin{tabular}{|c|c|c|c|c|c|}
\hline Characters & Caste & Treatment hrs & Control & JH-III & 20-E \\
\hline \multirow{4}{*}{ Weight (mg) } & \multirow{2}{*}{ Worker } & $24 \mathrm{hrs}$ & $55.6 \pm 1.02$ & $55.6 \pm 0.98$ & $56.62 \pm 0.74$ \\
\hline & & $36 \mathrm{hrs}$ & $56.08 \pm 0.92$ & $55.80 \pm 1.04$ & $57.22 \pm 1.40$ \\
\hline & \multirow{2}{*}{ Drone } & $24 \mathrm{hrs}$ & $58.00 \pm 1.05$ & $58.00 \pm 0.90$ & $58.77 \pm 1.03$ \\
\hline & & $36 \mathrm{hrs}$ & $59.03 \pm 0.33$ & $58.9 \pm 1.3$ & $61.23 \pm 1.81$ \\
\hline \multirow{4}{*}{ Length (mm) } & \multirow{2}{*}{ Worker } & $24 \mathrm{hrs}$ & $10.95 \pm 0.12$ & $10.95 \pm 1.17$ & $10.97 \pm 1.09$ \\
\hline & & 36hrs & $10.50 \pm 0.27$ & $10.86 \pm 1.03$ & $9.95 \pm 1.28$ \\
\hline & \multirow{2}{*}{ Drone } & $24 \mathrm{hrs}$ & $11.25 \pm 1.07$ & $11.25 \pm 0.27$ & $11.27 \pm 2.23$ \\
\hline & & $36 \mathrm{hrs}$ & $11.18 \pm 1.33$ & $11.42 \pm 1.35$ & $10.65 \pm 1.01$ \\
\hline
\end{tabular}




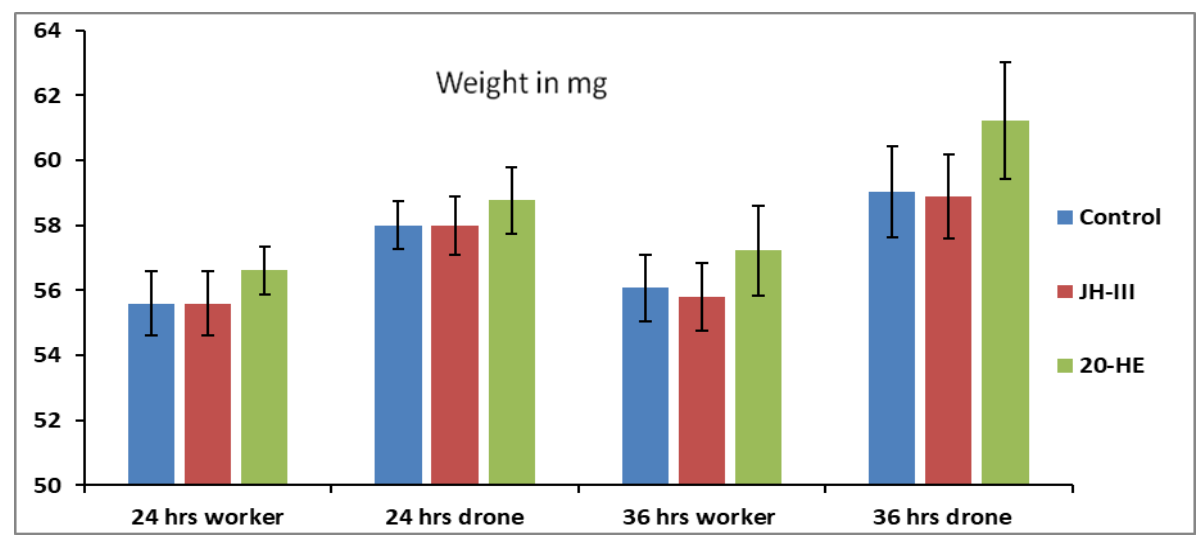

Fig 2: Graph represent the effect of juvenile hormone-III (JH-III) and 20-hydroxyecdysone (20-HE) on weight of fifth instar larvae of worker and drone honeybee Apis cerana indica at $24 \mathrm{hrs}$ and $36 \mathrm{hrs}$. Control treatment includes only acetone.

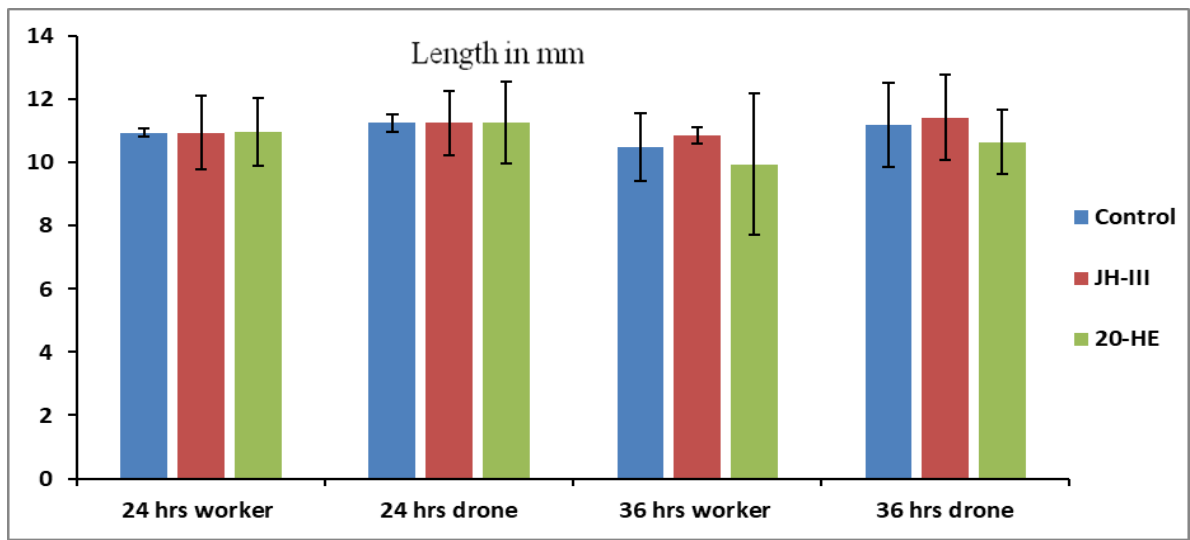

Fig 3: Graph represent the effect of juvenile hormone-III (JH-III) and 20-hydroxyecdysone (20-HE) on length of fifth instar larvae of worker and drone honeybee Apis cerana indica at $24 \mathrm{hrs}$ and $36 \mathrm{hrs}$. Control treatments include only acetone.

\section{Effect of JH-III and 20-HE on total body protein}

After $24 \mathrm{hrs}$ treatment with acetone and JH-III in fifth instar worker larvae, no significant change in total body protein concentration was observed but protein concentration was decrease in worker larvae treated with 20-HE. At 36 hrs decrease in total body protein concentration was observed in JH-III and 20-HE treated worker larvae as compared to control larvae treated with acetone.

In drone's fifth instar larvae protein concentration was decrease when larvae were treated with JH-III and 20-HE as compared to control larvae treated simply with acetone at 24 hrs and $36 \mathrm{hrs}$.

In fifth instar larvae of worker honeybee at $24 \mathrm{hrs}$ and $36 \mathrm{hrs}$, total body protein conc. of JH-III treated larvae was higher than 20-HE treated larvae but in drone's fifth instar larvae opposite effects of both hormone were seen in which 20-HE treated larvae were high total body protein conc. as compared to JH-III treated larvae. (Table 2 and Fig. 4)

Table 2: Showing total body protein concentration of fifth instar larvae of worker and drone honeybee after $24 \mathrm{hrs}$ and $36 \mathrm{hrs}$ treatment with acetone (control), Juvenile hormone-III (JH-III) and 20- hydroxyecdysone (20-HE).

\begin{tabular}{|c|c|c|c|c|}
\hline \multirow{2}{*}{ Caste } & \multirow{2}{*}{ Treatment hrs } & \multicolumn{3}{|c|}{ Total Protein concentration $(\mathbf{m g} / \mathbf{m l})$} \\
\cline { 2 - 5 } & & Control & JH-III & 20-HE \\
\hline \multirow{2}{*}{ Worker } & $24 \mathrm{hrs}$ & $5.25 \pm 0.12$ & $5.24 \pm 0.67$ & $4.59 \pm 0.11$ \\
\cline { 2 - 5 } & $36 \mathrm{hrs}$ & $5.11 \pm 0.52$ & $4.95 \pm 0.39$ & $4.52 \pm 0.74$ \\
\hline \multirow{2}{*}{ Drone } & $24 \mathrm{hrs}$ & $4.70 \pm 0.08$ & $4.44 \pm 1.77$ & $4.64 \pm 0.80$ \\
\cline { 2 - 5 } & $36 \mathrm{hrs}$ & $4.69 \pm 0.98$ & $4.36 \pm 0.33$ & $4.52 \pm 1.83$ \\
\hline
\end{tabular}

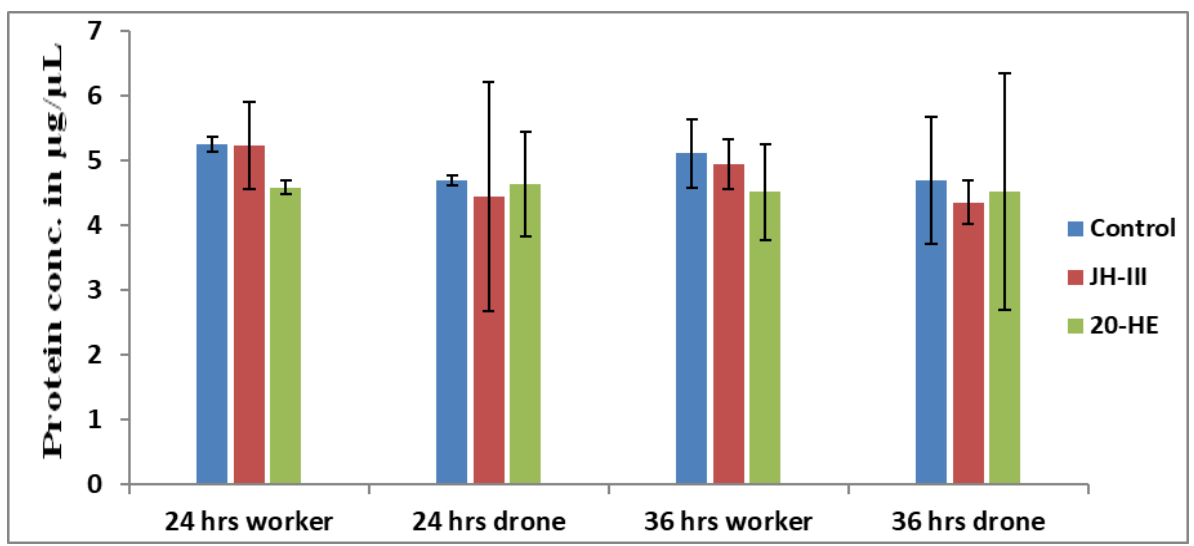

Fig 4: Showing total body protein concentration of fifth instar larvae of worker and drone honeybee Apis cerana indica after $24 \mathrm{hrs}$ and $36 \mathrm{hrs}$ treatment with acetone (control), Juvenile hormone-III (JH-III) and 20- hydroxyecdysone (20-HE). 


\section{Discussion}

Several workers reported the role of juvenile hormone during caste development of honeybee, Apis mellifera and in other social insects. (Wirtz and Beetsma, 1972; Shuel and Dixon, 1973; Wirtz, 1973; Copijn et al., 1979; Dietz et al., 1979; Rachinsky et al., 1990) [20, 21, 5, 6, 12]. Rembold et al., 1974 [13] suggested disturbed development in honeybee larvae treated by juvenile hormone. Salles and Cruz-Landim (2004) [15] concluded the response of exogenous application of hormones depend upon the type of organ involved, developmental parameters, developmental stages and amount of hormone applied. He found no effect of $\mathrm{JH}$ on development of mandibular gland of fifth instar larvae of worker honeybee Apis mellifera. Same concussion was made by Kubo et al., (1983) ${ }^{[10]}$ while studying effect of diet containing different concentration of ecdysteroids hormone on $2^{\text {nd }}$ instar larvae of Bombyx mori. Asencot and Lansky (1976) ${ }^{[1]}$ concluded that topical application of juvenile hormone with $4 \%$ glucose and $4 \%$ fructose differentiated the worker larvae to queen. In present study it was seen that topical application of JH-III had no prominent effect on weight on fifth instar larvae of worker and drone caste at $24 \mathrm{hrs}$ and $36 \mathrm{hrs}$ but 20-HE shows stimulatory effect on weight of larvae and weight gain was observed in both caste of larvae at $24 \mathrm{hrs}$ and $36 \mathrm{hrs}$ treatments. Slightly increase in length of fifth instar larvae of worker and drone castes were observed at $36 \mathrm{hrs}$ after JH-III treatment. Decrease in length of larvae of both castes was observed at $36 \mathrm{hrs}$ when larvae treated with 20-HE. After topical application of JH-III and 20-E, though pattern of effects of both hormones on worker and drone castes were similar but major changes in weight and length were observed in drone larvae and from this observation present study concluded that these changes are due to different developmental timing of worker and drone caste in colony.

Rutz et al., (1976) ${ }^{[14]}$ concluded increased and decreased in haemolymph protein and vitellogenin synthesis depends on the amount JH-III hormone injected. Colonella and Hartfelder (2003) ${ }^{[4]}$ found that protein content and protein pattern of mucus gland of drone honeybee after 20-hydroxyecdysone were decrease as compared to normal and saline treated mucus gland. Shridevi et al., (1988) observed stimulatory effects of 20-hydroxyecdysone on protein synthesis in male accessory reproductive gland of Spodoptera litura. Inhibitory and stimulatory effects of 20-hydroxyecdysone was also noticed in other insects (Ismail and Dutta-Guota, 1990; Ismail and Gillot 1995, 1997; Barsagade and Gharade 2014) ${ }^{[7,8,9]}$. Tozetto et al., (2007) [19] observed increased protein concentration parallel to increase in ecdysteroids level during prepupal to late pupal developmental stages in reproductive organ of drone honey bee Apis mellifera. In present study effect of JH-III and 20-HE after $24 \mathrm{hrs}$ and $36 \mathrm{hrs}$ treatment on total body protein concentration was observed inhibitory in both castes when compared with control larvae. In drone 20HE treated larvae show high protein concentration than JH-III treated larvae while in worker JH-III treated larvae show high protein conc. than $20-\mathrm{HE}$ treated larvae. From these observations present study concluded that different effects of JH-III and 20-HE on worker and drone larvae are due to the difference in physiology and larval development time of both castes.

\section{References}

1. Asencot M, Lansky Y. Effect of sugars and juvenile hormone on the differentiation of the female larvae (Apis mellifera L.) to queens. Life science 1976;18:693-700.

2. Barsagde DD, Gharade SA. Hormonal regulation of metamorphosis (Larva to Pupa) in the tropical tasar Silkworm Antheraea mylitta (D.) Eco-race Bhandara. Int. J. of Res. in Chem and Env 2014;4(4):69-74.

3. Bradford Marion M. A rapid and sensitive method for the quantification of microgram quantities of protein utilizing the principle of protein -dye binding. Anlytical Biochem 1976;72(1-2):248-254.

Doi:10.1006/abio.1976.9999.PMID 942051.

4. Colonello NA, Hartfelder. Protein content and pattern during mucus gland maturation and its ecdysteroids control in honeybee drones. Apidologie 2003;34:257267.

5. Copijn GM, Beetsma J, Wirtz P. Queen differentiation and mortality after application of different juvenile hormone analogues to worker larvae of the honeybee (Apis mellifera L) Proc. K. Ned. Akad. Wet. Ser. C. 1979;82:29-42.

6. Dietz A, Hermann HR, Blum MS. The role of exogenous JH - I, JH-III and anti - JH (Precocene II) on queen induction of 4.5 day - old worker honeybee larvae. Insect Physiol 1979;25:503-512.

7. Ismail PM, Dutta-Gupta A. effect of 20hydroxyecdysone on the protein synthesis in male reproductive glands of Chilo partellus. Biochem. Arch 1990;6:321-329.

8. Ismail PM, Gillot C. 20- Hydroxyecdysone and juvenile hormone regulation of specific protein synthesis in the male accessory reproductive gland of Melanoplus sanguinipes under in vitro condition. Insect Physiol 1995;41:911-920.

9. Ismail PM, Gillot C. Hormonal regulation of protein synthesis in the nymphal and adult male accessory reproductive gland of Locusta migratoria. Inv. repro. Dev 1997;31(1-3):275-283.

10. Kubo I, Klocke JA. Asano S. Effects of ingested phytoecdysteroids on the growth and development of two lepidopterous larvae. Insect Physiol 1982;29(4):307-316.

11. Nascimento AM, Cuvillier HV, Barchuk AR, Simoes ZLP, Hartfelder K. Honeybee (Apis mellifera) transferrin gene structure and the role of ecdysteroids in the development regulation of its expression. Insect Biochem and Mole. Bio 2004;34:15-424.

12. Rachinsky A, Stramb C, Stramb A, Hartfelder K. Caste and Metamorphosis: Haemolymph titers of Juvenile hormone and Ecdysteroids in Last Instar Honeybee Larvae. Gen and Comp. Endo 1990;79:31-38.

13. Rembold H, Czoppelt CH, Rao PJ. Effect of juvenile hormone treatment on Caste differentiation in the honeybee Apis mellifera. J Insect Physiol 1974;20:11931202. https://doi.org/10.1016/0022-1910(74)90225-X

14. Rutz W, Luscher M. The occurrence of vitellogenin in workers and queens of Apis mellifera and the possibilities of its transmission to the queen. Insect Physiol 1976;7:276 -347.

15. Salles HC, Cruz-Landim C. Effect of juvenile hormone on the development of the mandibular gland in worker pupae of Apis mellifera L. (Hymenoptera: Apidae). Braz. J. Biol 2004;64(3B):691-695.

16. Shuel RW, Dixon SE. Regulatory mechanism in caste development in the honeybee Apis mellifera L. Proc. VIIth Int. Cong. Social Insects, London 1973, 349-360.

17. Sridevi R, Bajaj P, Ray ADG. Ecdysteroid stimulated 
protein synthesis in the male accessory reproductive gland of Spodoptera litura, Invertebr. Reprod. Dev. 1988; 14:177-185.

18. Steel RGD, Torrie JH. (Principle and procedure of statistics with special reference to the biological science. McGraw Hill, New York 1960, 187-287.

19. Tozetto S DE O, Bitondi MMG, Dallacqua, Simoes ZLP. Proteins profiles of testes, seminal vesicles and accessory glands of honeybee pupae and their relation to the ecdysteroids titer. Apidologie 2007;38:1-11.

20. Wirtz, Beetsma. Induction of caste differentiation in the honeybee (Apis mellifera L) by juvenile hormone. Entomol. Exp. Appl 1972;15:517-520.

21. Wirtz Differentiation in the honeybee larva. Comm. Agric. Uni. Wageningen 1973, 73-75. 